\title{
EL CIUDADANO Y EL REFUGIADO EN LA OBRA DE AGAMBEN
}

\section{THE CITIZEN AND THE REFUGEE IN AGAMBEN'S WORK}

\author{
Mauro Benente *** $^{2}$ \\ Abogado \\ Universidad de Buenos Aires \\ maurobenente@yahoo.com \\ Argentina
}

\section{SUMARIO}

- Hannah Arendt. Apátridas, refugiados y derechos ciudadanos

- Derechos humanos y derechos ciudadanos. La silueta del refugiado en mirada de Giorgio Agamben

- Los límites de la emancipación política

- Notas finales. Los límites de la renovación categorial

\section{RESUMEN}

Tanto en el breve artículo titulado «Más allá de los derechos del hombre» como en Homo sacer I, Giorgio Agamben tematizó sobre la decadencia de los derechos del hombre retomando algunas de las líneas mecanografiadas por Hannah Arendt. En el presente trabajo, mi intención es dar cuenta de las aproximaciones de Arendt sobre la temática de los derechos del hombre a partir de la angustiante situación que aquejaba tanto a apátridas como a refugiados durante la primera parte del siglo xx. Luego, reseñaré el modo en que Agamben se apropia de estas argumentaciones y propone la figura del refugiado como matriz para una renovación categorial. Finalmente, a partir de algunas sospechas delineadas en la obra de Karl Marx, me interesará destacar los límites que presenta esta tan apremiante renovación categorial predicada por el autor italiano.

\section{PALABRAS CLAVE}

Derechos del hombre, derechos del ciudadano, nacionalidad, Estado

\begin{abstract}
Both in a short article entitled «Beyond human rights» and also in Homo sacer I, Giorgio Agamben argued about the decadence of human rights, taking up some lines typewritten by Hannah Arendt. In this piece of work, I intend to account for the approximations that Arendt made about the topic of human rights, based on the desperate situation that afflicted stateless and refugees during the early part of the twentieth century. Then I will summarize how Agamben takes over these arguments and proposes the figure of the refugee as a mold for a categorial renewal. Finally, based on some suspicions delineated in Karl Marx's work, I will stand out the limitations presented in this so urgent renewal categorial preached by the Italian author.
\end{abstract}

\section{KEYWORDS}

Rights of man, citizenship rights, nationality, state

\section{INTRODUCCIÓN}

Desde su primer artículo publicado en 1964 hasta la actualidad, la obra de Giorgio Agamben luce una notable amplitud de temas, preocupaciones, abordajes y tradiciones

\footnotetext{
** Doctor en Derecho (Universidad de Buenos Aires), becario posdoctoral del Consejo Nacional de Investigaciones Científicas y Técnicas, investigador del Instituto de Investigaciones Jurídicas y Sociales "A. L. Gioja.", docente de Teoría del Estado en la Facultad de Derecho de la Universidad de Buenos Aires y profesor titular ordinario de Filosofia del Derecho en la Universidad Nacional de José C. Paz. Coordinador del grupo de trabajo "Pensamiento jurídico crítico" del Consejo Latinoamericano de Ciencias Sociales.

Agradezco los comentarios y sugerencias que el Dr. Gino Augusto Tomás Ríos Patio realizó a una versión anterior de este trabajo.
} 
teóricas recuperadas. Sus primeros libros, El hombre sin contenido (1970), Estancias. La palabra y el fantasma en la cultura Occidental (1977), Infancia e historia. Destrucción de la experiencia y origen de la historia (1978), y El lenguaje y la muerte: un seminario sobre el lugar de la negatividad (1982), pueden ser vistos como una lectura de la modernidad, desde un registro que no es el de la teoría política, sino el de la estética.

Además, en estos trabajos se advierten tematizaciones estrictamente filosóficas alrededor del problema del lenguaje, el tiempo y la experiencia. ${ }^{1}$ Con Idea de prosa, publicado en 1985, y principalmente con La comunidad que viene, de 1990, el autor italiano avanza sobre problemas más relacionados con la teoría política, pero es a partir de la saga Homo sacer, iniciada en 1995, que se sumerge de lleno en las reflexiones sobre la (bio) política.

La saga, que todavía está en curso, se compone de los siguientes trabajos: El poder soberano y la nuda vida. Homo saber I (1995), Lo que resta de Auschwitz. El archivo y el testigo. Homo sacer III (1998), Estado excepción. Homo sacer II, 1 (2003), El reino y la gloria. Una genealogía teológica de la economía $y$ del gobierno. Homo sacer II, 2 (2007), El sacramento del lenguaje. Arqueología del juramento. Homo sacer II, 3 (2008); Altísima pobreza. Reglas monásticas y forma de vida. Homo sacer IV, 1 (2011); Opus dei. Arqueología del oficio. Homo sacer II, 5 (2012); El uso del cuerpo. Homo sacer IV, 2 (2014); Stasis. La guerra civil como paradigma político. Homo sacer II, 2 (2015). ${ }^{2}$

1 El hombre sin contenido presenta un abordaje del estatuto estético de la obra de arte, pero también una indagación sobre el obrar del hombre en general, detectándose una reducción de la poíesis a la praxis. En esta obra, Agamben da cuenta de la emergencia en el siglo xvir de los museos, en los cuales las obras de arte se distancian del espacio común de los hombres. La noción de museo, que se erige como un concepto técnico que alude al distanciamiento, a esta separación mencionada, será acuñada nuevamente por Agamben en Profanaciones, pero para referirse a la museificación del mundo. En Estancias aborda el problema del conocimiento en las ciencias sociales, disciplina en la cual sujeto y objeto se encuentran identificados, y se esbozan los conceptos de fetichismo y de uso, siendo esta última noción empleada en varios otros trabajos. En Infancia e historia, con una fuerte resonancia de los trabajos de Walter Benjamin, tematiza dos elementos que, a los ojos del autor italiano, están tratados de modo muy deficiente en la filosofia y en la politica moderna: la expropiación de la experiencia y la ausencia de una concepción del tiempo propia del hombre. Finalmente, en El lenguaje de la muerte se aborda con profundidad la temática de la voz y su doble negatividad: no más un sonido, todavíano un significado.

2 Paralelamente a la publicación de la saga Homo sacer, han aparecido otros trabajos que en general suelen ser
Dentro de la saga Homo sacer, El poder soberano y la nuda vida y Estado de excepción representan un esfuerzo por dar cuenta del nexo entre vida y soberanía, por mostrar la existencia de un vínculo constitutivo entre la soberanía y la vida reducida a su mera faceta biológica -que Agamben denomina nuda vida o vida desnuda-.

Fue en este marco que, en un breve artículo titulado «Más allá de los derechos del hombre», aparecido en Libération en junio de 1993, y luego incluido en Medios sin fin publicado en 1996, y en el capítulo II de la parte tercera de Homo sacer I. El poder soberano y la nuda, titulado «Los derechos del hombre y la biopolítica», tematizó sobre el asunto de los derechos del hombre. Si bien el gran aporte de Agamben a las reflexiones sobre el derecho se sitúa alrededor del problema de la soberanía y del estado de excepción, de modo relativamente lateral ha proyectado su horizonte de análisis a conceptos clave del ordenamiento jurídico occidental como los de derechos del hombre y ciudadanía, para lo cual ha seguido el sendero abierto por Hannah Arendt a mediados del siglo $\mathrm{xx}$.

En el presente trabajo mi intención es dar cuenta de las aproximaciones de Arendt sobre la temática de los derechos del hombre a partir de la situación que acosó a apátridas y refugiados a principios y mediados del siglo xx. Para ello no ha sido necesario abordar en profundidad toda su producción teórica, sino más bien leer con detalle un breve artículo titulado «Nosotros los refugiados», y el famoso capítulo IX de Los orígenes del totalitarismo. Según desarrollaré, el notable aporte de Arendt fue mostrar con total crudeza que la supuesta universalidad de los derechos del hombre se transformaba en una quimera cuando los individuos no lograban inscribirse bajo el manto de la ciudadanía estatal.

\footnotetext{
compilaciones de artículos breves, con un tono ensayístico, en los que se alude a diferentes temáticas, y algunos trabajos retoman asuntos de las investigaciones presentes en Homo sacer y también se brindan pistas para pensar una politica por fuera, o distinta y distante de, la biopolitica. Las publicaciones que han aparecido en simultáneo a la saga son Medios sin fin. Notas sobre la politica (1996); El tiempo que resta. Un comentario a la Carta a los Romanos (2000); Lo abierto. El hombre y el animal (2002); Profanaciones (2005), Ninfas (2007), La potencia del pensamiento (2007), Signatura Rerum. Sobre el método -2008-, Desnudez (2008); Angeles. Judaísmo, Cristianismo, Islam —editado en 2009 junto con Emanuele Coccia-; La iglesia y el reino (2010); El misterio del mal. Benedicto XVI y el fin de los tiempos (2013); El fuego y la historia (2014); ¿Qué es la filosofia? (2016).
} 
Luego de esta presentación, reseño el modo en que Agamben se apropia de los estudios de la autora nacida en Linden y, compartiendo las críticas dirigidas hacia la supuesta universalidad de los derechos humanos, propone la figura del refugiado como una matriz para una renovación categorial, como una alternativa al problemático concepto de ciudadanía. Nuevamente, para realizar mi cometido no resultó imperioso abordar la totalidad de los trabajos del autor italiano, pero sí me he detenido en el primer volumen de la saga Homo Sacer.

Finalmente, a partir de ciertas sospechas delineadas en la obra de Karl Marx — tratadas especialmente en Sobre la cuestión judía-, de aportes de autores como Juan Ramón Capella y John Holloway, y de un curioso episodio que se produjo en el 2011 en un banco de Carolina del Norte, marco los límites que presenta esta tan apremiante renovación categorial sobre la que insiste el autor italiano: aunque la eliminación del concepto de ciudadanía marca un interesante avance en la universalidad en el reconocimiento de los derechos humanos, ese progreso se mantiene en un registro eminentemente formal.

\section{HANNAH ARENDT. APÁTRIDAS, REFUGIADOS Y DERECHOS CIUDADANOS}

Hannah Arendt debió escapar del régimen nazi en 1933 y, tras pasar por Karlovy Vari, Génova y Ginebra, se estableció en la ciudad de París. En 1937, el régimen nazi le quitó su nacionalidad y en 1941 debió abandonar Francia, aunque afortunadamente pudo incluir dentro de su equipaje las Tesis sobre la historia de Walter Benjamín, que ya en los Estados Unidos fueron entregadas a Theodor Adorno. Luego de abandonar París, y tras una breve estadía en Lisboa, se radicó finalmente en Nueva York.

En los Estados Unidos escribió dos interesantes trabajos sobre la temática de los refugiados y los apátridas, asunto desde los cuales proyectó su crítica, su sospecha, al potencial de los derechos del hombre. El primero, We the refugees - Nosotros los refugiadosdata de enero de 1943. Escrito a muy poco de su llegada al país, fue publicado en una revista judía de lengua inglesa llamada The Menorah Journal. Su segundo trabajo, más conocido y profuso, corresponde al Capítulo
IX del segundo volumen de Los orígenes del totalitarismo -Imperialismo-, titulado «La decadencia del Estado nación y el final de los derechos del hombre», cuya primera edición data de 1951, año en que finalmente logró adoptar la nacionalidad estadounidense luego de ser, durante catorce años, un apátrida. En el transcurso de esa década y media, al no contar con derechos ciudadanos tampoco contaba con los derechos del hombre.

El primero de los trabajos podría leerse como un escrito testimonial, redactado en primera y en tercera persona, que intenta dar cuenta de las experiencias comunes de los emigrados judíos de la Alemania nazi. Narrado con una poderosa carga emotiva, se trata del testimonio de quienes, como ella, rehusaban autodenominarse refugiados y preferían la referencia de recién llegados o inmigrantes (Arendt, 1994, p. 110). Estas muy agudas líneas no son otra cosa que una escalofriante descripción del infierno que acosaba a quienes escapaban del nacionalsocialismo: un infierno «que ya no es una creencia religiosa ni una fantasía, sino algo tan real como las cosas, las piedras y los árboles» (ibid., p. 111). Un abismo con «un nuevo tipo de ser humano - que es confinado en campos de concentración por sus enemigos y en campos de internamiento por sus amigos-» (ibid., p. 111).

En esta narración testimonial ya aparece un atisbo de aquello que será profundizado ocho años más tarde en Los orígenes del totalitarismo: la desprotección legal que los judíos sufrían al emigrar. En este sentido, la autora narra que si contáramos «que no somos más que judíos, ello significaría exponernos al destino de los seres humanos que, desprotegidos por la ley o convención política específica, no son nada más que seres humanos» (ibid., p. 118). Esto es así porque «los pasaportes o los certificados de nacimiento, y a veces incluso los recibos del impuesto sobre la renta, ya no son papeles oficiales, sino cuestiones de distinción social»» (ibid., pp. 118-19). Años más tarde, retomado algunos de estos vestigios, Arendt profundizará sus reflexiones sobre la temática e indagará, ya con más herramientas y precisiones teóricas, el peso de algo a primera vista tan liviano como un certificado de nacimiento.

En los Orígenes del totalitarismo, antes de analizar la situación de los apátridas y refugiados, Arendt afirma que la emergencia de 
los tratados sobre protección de minorías étnicas y/o nacionales celebrados con posterioridad a la Primera Guerra Mundial se erigía como una muestra clara de lo que otrora no era más que un indicio, una huella, algo que solamente estaba implícito: solo los nacionales podían ser ciudadanos y únicamente ellos podían gozar de una completa protección legal. En los mismos tratados de minorías se contemplaba que la protección de los no-nacionales no sería una obligación de los Estados nación, sino de la recientemente creada Sociedad de Naciones (ibid. pp. 272-275).

La descripción de Arendt se intensifica en profundidad, pero también en dramatismo cuando sus desarrollos se trasladan del análisis de la situación de las minorías hacia la problemática de los refugiados y apátridas, momento en el cual los derechos supuestamente inalienables mostraban a todas luces que solo podían ser disfrutados por los ciudadanos de las naciones más prósperas. En los Estados totalitarios, la desnacionalización se convirtió en un arma sumamente eficaz, eficacia posibilitada, paradójicamente, no solo por la práctica de los totalitarismos, sino también por la incapacidad de los Estados nación democráticos para dar protección legal a quienes no eran nacionales -máxime cuando el derecho de asilo comenzó, poco a poco, a ser abolido —.${ }^{3}$ En este orden de ideas, afirma que:

\section{Ninguna paradoja de la política contemporánea está cargada de una ironía tan patética como la discrepancia entre los esfuerzos de idealistas bien intencionados que insistieron tenazmente en considerar como «inalienables» aquellos derechos humanos, que eran disfrutados solamente por los ciudadanos de los países más prósperos y civilizados, y la situación de quienes carecían de tales derechos (Arendt, 1962, p. 279).}

Este panorama se volvió más escalofriante cuanto la situación de los apátridas se fue deteriorando y "el campo de internamiento - que antes de la Segunda Guerra Mundial era la excepción más que la norma para los apátridas_ - se transformó en la solución

\footnotetext{
3 Así se lee que "aquellos a quienes el perseguidor habia individualizado como la escoria de la Tierra -judios, trotskistas, etc. - fueron recibidos en todas partes como escoria de la Tierra; aquellos a quienes la persecución habia calificado de indeseables, se transformaron en los indésirables [indeseables] de Europa" (Arendt, 1962, p. 279).
}

de rutina para el problema del domicilio de las «personas desplazadas»" (Arendt, 1962, p. 279). Los apátridas y refugiados eran una denuncia viva, una falla materializada en sufrimiento, de un discurso que hacía alusión a la universalidad de unos derechos humanos que solo funcionaban como derechos ciudadanos. Cuando fueron puestos a prueba, cuando debieron aplicarse a los apátridas, a aquellos que ya no tenían otro atributo que su sola pertenencia a la humanidad, los derechos humanos quedaron reducidos a los derechos ciudadanos (Amiel, 2000, p. 28).

La identidad, la reducción de los derechos del hombre a los derechos del ciudadano privaba a los no-ciudadanos del derecho a tener derechos. ${ }^{4}$ Estaban por fuera del derecho, e incluso $-\mathrm{y}$ esto muestra la crudeza del problema- el único modo de entrar al ámbito de la ley era por vía del delito. En este sentido, Arendt (1962) propone realizar un escalofriante test:

El mejor criterio por el que decidir si alguien se ha visto expulsado del ámbito de la ley es preguntarle si se beneficiará cometiendo un delito. Si un pequeño hurto es probable que mejore, al menos temporalmente, su posición legal, se puede estar seguro de que ese individuo ha sido privado de sus derechos humanos. Porque entonces un delito se convierte en la mejor oportunidad de recuperar algún tipo de igualdad humana, aunque sea como reconocida excepción a la norma (p. 286). ${ }^{5}$

Aquello que Arendt (1962) intenta exponer a partir de la situación de las minorías, pero principalmente atendiendo al escándalo de los refugiados y apátridas, es que mientras los derechos del hombre se habían consagrado como inalienables e independientes de todo gobierno, realmente no revestían esos atributos (p. 293). ${ }^{6}$ De esta manera, «los Derechos

4 Benhabib (2004) realiza un interesante análisis de la expresión "derecho a tener derechos" y muestra que la noción de derecho no se emplea en el mismo sentido en los dos casos (pp. 56-61).

5 En la misma línea se lee que como el apátrida "era la anomalía para quien la ley general nada proporcionaba, para él era mejor convertirse en una anomalía a la que atendía la ley, es decir, en un delincuente" (Arendt, 1962, p. 286).

6 Asíla completa implicación de esta identificación de los derechos del hombre con los derechos de los pueblos en el sistema europeo del Estado nación surgió a la luz únicamente cuando aparecieron repentinamente un creciente número de personas y de pueblos cuyos derechos elementales se hallaban tan poco salvaguardados por el funcionamiento ordinario de los Estados nación en el centro de Europa, como lo habrian sido en el corazón de África. Los Derechos 
The citizen and the refugee in Agamben's work

del Hombre, supuestamente inalienables, demostraron ser inaplicables [unenforceable] -incluso en países cuyas Constituciones estaban basados en ellos- allí donde aparecían personas que no eran ciudadanas de ningún Estado» (ibid., p. 293). El escándalo que implica la situación de los fuera de la ley no es la privación de su felicidad, ni de la igualdad ante la ley, sino de un escenario de no-pertenencia a la comunidad: «su situación no es la de no ser iguales ante la ley, sino que no existe ley para ellos» (ibid. pp. 295-296). Por esto puede decirse que «no fue la pérdida de derechos específicos, sino que fue la pérdida de una comunidad que quiera y este capacitada para garantizar cualquiera de los derechos la calamidad que ha sobrevenido a un siempre creciente número de personas» (ibid., p. 297).

Sin dudas, el relato histórico que realiza Arendt resulta sumamente importante, pero sus líneas no construyen solamente una narración con pretensiones empíricas, sino que también intentan imponer una manifestación de principios. De acuerdo con lo expuesto por Étienne Balibar (2007) en el marco del coloquio Hidden Tradition-Untimely Actuality?, celebrado con ocasión de la conmemoración de los cien años del nacimiento de la autora, la potencia de sus postulados radica en mostrar con notable énfasis que «si la abolición de los derechos del ciudadano significa también la destrucción de los derechos del hombre, es porque en realidad los segundos reposan sobre los primeros y no a la inversa» (p. 92). Este reposo de los derechos del hombre sobre los derechos ciudadanos parece confirmarse cuando Arendt (1962) muestra que así como la pérdida de los derechos nacionales implicó el quebranto de los derechos humanos, «la restauración de los derechos humanos, como lo prueba el reciente ejemplo del Estado de Israel, solo ha sido lograda hasta ahora a través de la restauración o el establecimiento de los derechos nacionales» (p. 299).

Reseñadas las reflexiones de Arendt sobre la temática de los derechos del hombre, apuntado el desajuste entre los derechos humanos y los derechos ciudadanos, o más bien el asiento

del Hombre, después de todo, habian sido definidos como inalienables porque se suponía que eran independientes de todos los Gobiernos: pero resultó que, al momento en que los seres humanos carecian de su propio Gobierno y tenian que recurrir a sus minimos derechos, no quedaba ninguna autoridad para protegerles ni ninguna institución estaba dispuesta a garantizarlos" (ibid., pp. 291-292). de aquellos sobre estos, es momento de presentar las líneas, escasas, pero poderosas, que Giorgio Agamben traza sobre la temática de los derechos del hombre, la ciudadanía, y la figura del refugiado.

\section{DERECHOS HUMANOS Y DERECHOS CIUDADANOS. LA SILUETA DEL REFUGIADO EN MIRADA DE GIORGIO AGAMBEN}

Agamben rescata el modo en que Arendt había mostrado cómo el refugiado, que debiera haber encarnado la figura central de los derechos del hombre, muy por el contrario no ha implicado más que su decadencia: los pretendidos derechos sagrados e inalienables habían perdido toda exigibilidad cuando no habían logrado configurarse como derechos ciudadanos. Es a partir de la silueta del refugiado — quizás podría afirmarse que Arendt había trabajado con mayor detalle la situación de los apátridas que la de los refugiados - que Agamben soplará acarreando nubes tormentosas sobre la entidad de los derechos del hombre. Siguiendo la línea de la autora alemana, y radicalizando el trazo de la argumentación, para Agamben (1998) el apoyo de los derechos humanos sobre los derechos ciudadanos, se encuentra implícita en la propia Declaración de los derechos del hombre y del ciudadano de 1789:

Donde no está claro si los dos términos sirven para denominar dos realidades autónomas o forman un sistema unitario, en el que el primero está ya siempre contenido en el segundo y oculto por él; $y$, en este último caso, qué tipo de relaciones mantienen entre ellos (p. 161). ${ }^{7}$

Para Agamben es menester dejar de concebir las declaraciones de derechos como simples proclamaciones de valores metajurídicos y suprahistóricos, y dar cuenta de su papel histórico en la constitución de los Estados nación (Castro, 2008, pp. 59-60). Para el autor italiano, «las declaraciones de derechos representan la figura originaria de la inscripción de la vida natural en el orden jurídico-político del Estado nación» (Agamben, 1998, pp. 161-162).

\footnotetext{
7 En este contexto "la boutade ['broma'] de Burke, que a los derechos inalienables del hombre declaraba preferir con mucho sus derechos de inglés (Rights of an Englishman), adquiere en esta perspectiva una insospechada profundidad", (Agamben, 1998, p. 161). La referencia a Burke también en Arendt (1962, p. 299).
} 
La nuda vida, esa simple vida natural, que en el mundo clásico se distinguía de la vida política $\mathrm{y}$ en el antiguo régimen era completamente indiferente, en la modernidad se convierte en el fundamento de la legitimidad del Estado. Así si analizamos la Declaración de derechos del hombre y del ciudadano advertimos que «es propiamente la vida natural, es decir, el puro hecho del nacimiento, lo que se presenta aquí como fuente portadora del derecho» (ibid., pp. 161-162).

Retrocediendo temporalmente algo más de un siglo, y trasladándose de Francia a Inglaterra, Agamben postula que ya en el Writ of Habeas corpus de 1679 podía advertirse esta politización de la nuda vida, esta inscripción de la vida desnuda en la esfera del poder soberano. Así en un pasaje de su obra, en el que extraña y livianamente inscribe al Writ of Habeas corpus dentro de una tradición democrática, se lee que el primer registro de la nuda vida como sujeto político se halla en el Writ of habeas corpus donde la referencia no es hacia el sujeto de relaciones y libertades feudales, ni hacia el ciudadano de la modernidad, sino hacia el corpus: «el nuevo sujeto de la política no es ya el hombre libre, con sus prerrogativas y estatutos, y ni siquiera simplemente homo, sino corpus, la democracia moderna nace como reivindicación y exposición de este cuerpo» (ibid., p. 175).

Para el autor italiano hay que considerar las declaraciones de derechos como un registro de la transición de la soberanía real a la soberanía nacional, y es necesario remarcar que fueron estas declaraciones las que permitieron que el súbdito se transformara en ciudadano, convirtiéndose así el mero nacimiento, la simple nuda vida, en portadora de la soberanía. De este modo, la situación de los refugiados en el siglo $\mathrm{xx}$, el drama de aquellos que estaban desprovistos de ciudadanía, no hace más que mostrar que la nuda vida era la cifra secreta de los derechos del hombre (Rancière, 2004, p. 300).

Esta inscripción de la vida en el dominio de la soberanía, posibilitada y articulada por los derechos del hombre, podría mostrar cierta ineptitud de estas herramientas jurídicas. En este sentido, Andrew Neal (2007) sugiere que los derechos y las libertades que deberían funcionar para proteger a los individuos frente a la opresión soberana «hacen totalmente lo contrario [...] no pueden ser opuestos a la excepción soberana porque esas libertades y derechos ya están incluidos en el dominio del poder soberano» (p. 9).

No obstante, en los escritos de Agamben no solamente se anuncia y enfatiza una supuesta inutilidad de los derechos del hombre para hacer frente a los abusos del poder soberano. El diagnóstico es notablemente más grave puesto que no expone la ineficacia de los derechos humanos frente a los abusos de poder, sino que presenta una supuesta continuidad entre la declaración de derechos y la opresión soberana:

Si se comprende esta función histórica esencial de las declaraciones de derechos, es posible llegar a entender también su desarrollo y sus metamorfosis en nuestro siglo. El nazismo y el fascismo, dos movimientos biopolíticos en sentido propio, es decir, que hacen de la vida natural el lugar por excelencia de la decisión soberana, surgen cuando, tras la gran convulsión de los fundamentos geopolíticos de Europa subsiguiente a la Primera Guerra Mundial, sale a la luz la diferencia hasta entonces oculta entre nacimiento y nación, y el Estado nación entra en una crisis duradera (Agamben, 1998, p. 163).

$\mathrm{Si}$ ya parecía que Agamben radicalizaba algunas de las posturas esgrimidas por Arendt, la línea de continuidad entre derechos del hombre, nazismo y fascismo -a los que parece tratar de modo indistinto - implica una fuerte redefinición. El filósofo italiano, dando cuenta de la inscripción de la nuda vida en el poder soberano que implicarían los derechos del hombre, sentencia que los dramas del fascismo y el nazismo "solo se hacen plenamente inteligibles cuando se sitúan a la luz del trasfondo biopolítico inaugurado por la soberanía nacional y las declaraciones de derechos» (Agamben, 1998, p. 165).

Además de utilizarla para reflexionar sobre los derechos del hombre, Agamben presenta una densa aproximación a la noción misma de refugiado y a su potencial para avanzar en una renovación de las categorías de la teoría jurídico-política moderna y contemporánea. En la misma línea que Arendt, entiende que «la paradoja está aquí en que precisamente la figura - el refugiado - que habría debido encarnar por excelencia los derechos del 
The citizen and the refugee in Agamben's work

hombre, marca por el contrario la crisis radical de este concepto» (Agamben, 2001, p. 24) ${ }^{8}$

Si en el marco de los Estados nación modernos la figura del refugiado resulta tan compleja es porque «al romper la continuidad entre hombre y ciudadano, entre nacimiento y nacionalidad, ponen en crisis la ficción originaria de la soberanía moderna» (Agamben, 1998, p. 167). Luego de la primera Guerra Mundial, el nexo nacimiento-nación comienza a disociarse, algo que puede detectarse en el número de Estados europeos que dictaron leyes de desnaturalización y desnacionalización de sus propios ciudadanos y, en la misma línea, el nazismo solo enviaba a los campos de exterminio a los judíos que antes hubiesen sido debidamente desnacionalizados. ${ }^{9}$

La separación entre lo humanitario y lo político no es otra cosa que la fase extrema de separación entre los derechos del hombre y del ciudadano $\mathrm{y}$, por ello, las organizaciones humanitarias, que comprenden la vida humana en los términos de una nuda vida, «mantienen, a pesar suyo, una secreta solidaridad con las fuerzas que tienen que combatir» (ibid., p. 169).

Como destaca Volker Heins (2005), esta afirmación supone cuatro proposiciones que son cuestionables tanto desde un plano empírico cuanto desde un registro conceptual: a) que la distinción entre lo humanitario y lo político es una expresión de la oposición entre derechos humanos y derechos ciudadanos; b) que el objetivo de las organizaciones humanitarias es la identificación y la preservación de la nuda vida; c) que a causa de su dependencia con la división entre lo político y lo humanitario, las organizaciones humanitarias se vuelven,

8 Como bien resume Slavoj Zizek (2005), la pregunta de fondo es "¿Qué les sucede, entonces, a los derechos humanos cuando son los derechos del homo sacer, de los excluidos de la comunidad politica; es decir, cuando ya no son de utilidad, ya que son los derechos de aquellos que, precisamente, no tienen derechos, y son tratados como inhumanos?" (p. 127).

9 Esta situación "pone de manifiesto que el nexo nacimientonación sobre el que la declaración del 89 había fundado la nueva soberania nacional, habia perdido ya su automatismo y su poder de autorregulación. Por una parte, los Estados nación llevan a cabo una reinserción masiva de la vida natural, estableciendo en su seno la discriminación entre una vida auténtica, por así decirlo, y una nuda vida, despojada de todo valor político (el racismo y la eugenesia nazi solo son comprensibles si se restituyen en este contexto); por otra, los derechos del hombre, que solo tenian sentido como presupuesto de los derechos del ciudadano, se separan progresivamente de aquellos y son utilizados fuera del contexto de la ciudadanía con la presunta finalidad de representar y proteger una nuda vida, expulsada en medida creciente a los márgenes del Estado nación y recodificada, más tarde, en una nueva identidad nacional" (Agamben, 1998, p. 168). sin darse cuenta, cómplices de aquellos sufrimientos sociales que apuntan a minimizar; y d) que la separación entre lo político y lo humanitario puede y debería superarse en favor de algo completamente nuevo (pp. 847-848).

Más allá de estas deficiencias, Agamben no solamente sugiere que las organizaciones supranacionales mantienen una solidaridad con aquello que pretenden combatir, sino que, ese aquello no es otra cosa que los campos de concentración: la separación entre lo humanitario y lo político solamente puede «reproducir el aislamiento de la vida sagrada sobre el que se funda la soberanía, y el campo de concentración, es decir, el espacio puro de la excepción, es el paradigma biopolítico que no consigue superar» (Agamben, 1998, p. 170).

El lugar del refugiado, a partir del cual Agamben cubre con mantos de sospecha la entidad de los derechos del hombre, es también el espacio desde donde predica un nuevo horizonte, una buena nueva. El refugiado debería ser tenido como «un concepto límite que pone en crisis las categorías fundamentales de la Nación Estado, desde el nexo nacimiento-nación hasta el de hombre ciudadano»" (Soto Carracedo, 2010 , p. 252), y es poniendo en crisis las categorías fundantes del Estado nación que «permite desterrar este terreno para dar paso a una renovación categorial que ya no admite demoras» (Agamben, 2001, p. 27).

Dentro de esta supuesta necesidad de renovación categorial, Agamben muestra - como es su costumbre en pocas líneas - que una de las posibilidades que tras la Segunda Guerra Mundial se tuvieron en cuenta para solucionar el problema de Jerusalén fue que la ciudad se transformara en la capital de dos Estados distintos. Esta paradójica condición de aterritorialidad podría generalizarse $\mathrm{y}$ en lugar de Estados separados por fronteras podrían imaginarse comunidades políticas ubicadas en una misma región pero «en situación de mutuo éxodo, articuladas entre ellas por una serie de extraterritorialidades recíprocas, en que el concepto guía no sería ya el ius del ciudadano, sino el refugium del individuo» (ibid., pp. 28-29).

Aplicando este salvataje categorial al continente europeo, su territorio podría considerarse como un espacio aterritorial en el cual los residentes de todos los Estados, sean o, no ciudadanos «estarían en situación de éxodo o de refugio y en el que el estatuto del europeo significaría el estar-en-éxodo (por supuesto también en la 
inmovilidad) del ciudadano» (ibid., p 29). Es en esta misma línea que en el marco de un debate acaecido luego de una conferencia pronunciada por Zygmunt Bauman en el Centro de Cultura Contemporánea de Barcelona el 11 de noviembre de 2005, afirmaba que la categoría de ciudadanía le parecía desesperanzada y desesperada, y entonces «la del refugiado - y pensaba en la concepción original del término como alguien que busca y encuentra refugiose me antoja una condición menos desesperada» (Agamben, 2008, p. 130).

Agamben se apropia y hace suyas las sospechas que Arendt había trazado, a partir de la situación de los apátridas y refugiados, sobre los derechos del hombre. Pero, además de radicalizar esta sospecha hasta el grado de proclamar una continuidad entre los derechos del hombre y nada más ni nada menos que el fascismo y el nazismo, presenta la categoría del refugiado como un potente puntapié para avanzar en una renovación categorial de la teoría jurídico-política moderna y contemporánea. Lo que ahora me interesa es problematizar y presentar ciertos límites de esta renovación categorial, para lo cual trabajaré alrededor de algunos elementos conceptuales que pueden extraerse de Sobre la cuestión judía.

\section{LOS LÍMITES DE LA EMANCIPACIÓN POLÍTICA}

Sobre la cuestión judía es un trabajo temprano en la obra de Karl Marx y fue publicado en París, en 1844, en el primer y único volumen de los Anales Franco-Alemanes. Se trata de una respuesta a un artículo de Bruno Bauer quien se había formado con Hegel y había sido profesor del propio Marx en la Universidad de Berlín- escrito en 1843 y titulado La cuestión judía. Poco tiempo más tarde, en compañía de Friedrich Engels, Marx también polemizó con Bauer en La sagrada familia, ${ }^{10}$ texto publicado en 1845 , y en La ideología alemana, escrito entre 1845 y $1846 .{ }^{11}$

10 No es casual que La Sagrada Familia, primera obra escrita en conjunto por Marx y Engels, lleve como subtitulo Crítica de la critica critica contra Bruno Bauer y consortes. El trabajo es una respuesta a las publicaciones que desde 1843 aparecian en la Literaturzeitung [Gaceta Literaria], dirigida por los hermanos Edgar, Egbert y Bruno Bauer. Es especialmente en los capítulos VI y VII donde se condensan las críticas hacia Bruno Bauer (Marx y Engels, 2013, pp. 102-199).

11 La ideología alemana lleva como subtitulo Crítica a la novisima filosofía alemana en las personas de sus representantes Feuerbach, B. Bauer y Stirner, y del socialismo alemán en las de sus diferentes profetas. Es en el capitulo II, titulado "San Bruno", que Marx y Engels polemizan con Bauer (Marx y Engels, 2005, pp. 97-121).
Los desarrollos de Bauer apuntaban a mostrar las dificultades del tipo de emancipación que pretendían los judíos alemanes, a quienes las normas les garantizaban menos derechos y fundamentalmente les impedían ingresar a la función pública: a) la primera dificultad radicaba en el sujeto emancipador puesto que el Estado, en Alemania, todavía no era un Estado laico; b) la segunda apuntaba al sujeto a emanciparse, puesto que el judío, por su propia esencia, tenía dificultades para emanciparse. Su esencia religiosa impedía tal emancipación.

Frente a estas dificultades, Bauer proponía que los judíos privatizaran su religión, relegaran a una esfera privada sus deberes y prácticas religiosas para obtener así iguales derechos en el plano estatal. Frente a esta posición, Marx enuncia ya no solamente los obstáculos de una eventual emancipación política de los judíos, sino que plantea directamente los límites de la idea misma de emancipación política.

Tras sugerir que la cuestión judía se presenta de modo diverso en Alemania, Francia y Estados Unidos, muestra que incluso en este último caso, es decir ante la presencia de un Estado emancipado políticamente, de un Estado que no impone creencias religiosas ni el modo de practicar el culto, es posible advertir la presencia de una población con fuertes sentimientos religiosos. Frente a este ejemplo histórico, como destaca Wendy Brown (1995), la objeción que Marx le realiza a Bauer marca que «tanto el Estado como el judío podrían renunciar a su prejuicio religioso y al hacerlo estar emancipados politicamente, sin haber sido emancipados de la religión» (p. 103).

Para Marx, la religión no se erige como el fundamento, sino como uno de los síntomas del fenómeno, más amplio, de los límites de la emancipación política. Estos se muestran en la situación que se presenta en los Estados Unidos: el Estado puede ser libre sin que el hombre lo sea. El Estado puede ser laico, pero no por ello los individuos lo serán. Esto es así porque el problema de la relación entre la emancipación política y la religión no es más que un capítulo de la relación entre la emancipación política y la emancipación humana: «la emancipación política de la religión no es la completa e incontrovertible emancipación de la religión, porque la emancipación política no es el modo completo y exento de contradicciones de la emancipación humana» (Marx, 2004, p. 17). 
The citizen and the refugee in Agamben's work

Los límites de la emancipación política se relacionan y se anudan con la separación entre el Estado y la sociedad civil. Con esta escisión los hombres poseen una doble vida: en el Estado son participantes de una comunidad política en la cual son considerados seres iguales y colectivos, mientras que en el ámbito de la sociedad civil se comportan como hombres privados, aislados y guiados por sus intereses egoístas. En este sentido, «el Estado político perfecto es, según su esencia, la vida genérica del hombre en oposición a su vida material» (Marx, 2004, p. 19). ${ }^{12}$ El problema radical que tiene la propuesta emancipadora de Bauer, entonces, es que continúa reproduciendo el esquema binario Estado-sociedad civil. La emancipación política es un progreso, pero no representa la forma última de emancipación humana, y retornando a la cuestión específica del debate con Bauer, eso explica por qué no logra acabar con la religiosidad del hombre.

En lo que me interesa remarcar, es menester tener presente que esta disociación entre Estado y sociedad civil se actualiza en la escisión entre derechos del hombre y derechos del ciudadano: «los droits de l'homme, a diferencia de los droits du citoyen, no son otra cosa que los derechos del miembro de la sociedad civil, es decir, del hombre egoísta, del hombre separado del hombre y la comunidad» (ibid., p. 31). Los derechos de igualdad, libertad, seguridad y propiedad, protegen al hombre únicamente en su faceta de integrante de la sociedad civil. ${ }^{13}$

De todos modos, el panorama es más problemático porque los derechos del hombre se limitan a proteger al individuo egoísta de la sociedad civil, pero además en la medida en que la comunidad política se erige como un mecanismo de protección de tales derechos, ella no hace más que configurarse como un simple medio para resguardar los comportamientos

12 En el mismo orden de ideas, en La sagrada familia Marx y Engels (2013) sostenían que "el Estado no es, por lo tanto lo que mantiene reunidos a los átomos de la sociedad burguesa; es el hecho de que esos átomos no son átomos más que en la representación, en el cielo de su imaginación, y que, en realidad, son entidades muy diferentes a los átomos: no son egoístas divinos, sino hombres egoístas. Únicamente la superstición política puede imaginar en nuestros dias que la vida burguesa es mantenida por el Estado, mientras que, por el contrario, el Estado es mantenido por la vida burguesa" (p. 153).

13 De acuerdo con Marx (2004) "ninguno de los derechos de hombre, por tanto, va más allá del hombre egoísta, del hombre tal como es, miembro de la sociedad civil, es decir, del individuo replegado de sí mismo, en su interés privado y en su arbitrariedad privada, y disociado de la comunidad (p. 43). egoístas de la sociedad civil. De acuerdo con la lectura que propone Marx, «la artimaña de poder que es propia del constitucionalismo liberal se centra en reconocer libertad, igualdad y representación a sujetos abstractos en lugar de sujetos concretos» (Brown, 1995, p. 106).

En el marco de esta separación de esferas, Marx propone una división entre derechos ciudadanos y derechos del hombre, mostrando que los derechos de propiedad, seguridad, libertad e igualdad, incluidos en la Declaración de 1789 y en las Constituciones francesas de 1791, 1793 y 1795, no eran derechos ciudadanos, sino derechos del hombre en tanto miembros de la sociedad civil. Sin embargo, incluso asumiendo que alguno de esos derechos estuviera en condiciones de adquirir alguna faz como derecho ciudadano y también suponiendo la igualdad en el plano de derechos ciudadanos, las limitaciones se mantienen en pie.

Si tomamos el caso del derecho a la igualdad, Marx (2004) afirma que cuando no se la considera en su sentido político no es otra cosa que «la igualdad de la liberté [...] todo hombre está igualmente considerado como una mónada que, como tal, reposa sobre sí misma» (p. 33).

No obstante, declarar la igualdad en el plano político, en el plano de los derechos ciudadanos, haciendo total abstracción de la sociedad civil y del egoísmo que engendra, también resultaría problemático. Así que, como destaca Capella (1997), uno de los ejes centrales del discurso político de la modernidad es la separación entre una esfera: una pública y otra privada. Si bien en esta última hay diferencias de sexo, género, clase, religión, educación, entre otras, estas no aparecen en el plano público, lo que implica que «lo público o político es así general o común a todos: en la esfera pública no hay hombres, sino -como veremos-, ciudadanos» (p. 111).

En esta línea, el jurista español distingue dos operaciones secuenciales para concebir a los integrantes de una población como ciudadanos iguales: 1) hacer abstracción de las diferencias físicas y sociales; y 2) concluida esta abstracción, dotar a los individuos de derechos. Los individuos se desprenden de numerosas cualidades que imperan en la esfera privada y solamente así pueden mostrarse como iguales y dotados de los mismos derechos en la esfera pública (pp. 113114). Esta operación nos muestra que incluso suponiendo que la igualdad consagrada no sea en 
términos de derechos del hombre sino en el plano de los derechos del ciudadano, la problemática se mantiene intacta. ${ }^{14}$

Si en los desarrollos de Capella se percibe que la igualdad en el plano de lo público o político confirma y reproduce la desigualdad en el ámbito de lo privado, en la obra de John Holloway (1994) esta misma situación se describe con una tinta marcadamente marxista, ya que «el principio de la igualdad ciudadana expresa y confirma la dominación de la clase capitalista» (p. 106). En la medida en que se trata a individuos desiguales como si fueran iguales, la noción de «ciudadanía se basa en, y refuerza, un cuadro ideológico que muestra una sociedad compuesta por una masa de individuos iguales, cuadro que niega la existencia de clases estructuradas de forma antagónica» (Holloway, 1994, p. 106). Desplazando las oposiciones de Estado y sociedad civil y público y privado, por la de político y económico, Holloway (1994) sugiere:

Solo se puede hablar de una sociedad compuesta por una masa de individuos iguales si nos abstraemos de las relaciones de producción, si cerramos los ojos a la explotación sobre la que se basa la sociedad capitalista, si hacemos una distinción tajante entre la ciudadanía y el Estado, por un lado, y lo que sucede en la fábrica, por el otro. El concepto de ciudadanía precisamente implica hacer una clara delimitación entre el Estado y las relaciones sociales de producción. El concepto de

14 Aunque de manera más rudimentaria, las advertencias sobre las limitaciones de la igualdad formal también pueden encontrarse en la obra de Marx. En este sentido, al momento de problematizar la idea de una distribución equitativa de los bienes de acuerdo con el aporte del trabajo realizado, tal como se proponía en el proyecto del Programa de Gotha al cual criticó muy enérgicamente-, Marx (1973) entendía que "este derecho igual es un derecho desigual para un trabajo desigual. No reconoce diferencia de clases, porque todo miembro de la sociedad es un trabajador como los demás, pero admite tácitamente como privilegio natural la desigualdad de aptitudes individuales y, por consiguiente, la desigualdad de la capacidad productiva. Asi, pues, por su contenido, como todos los derechos, es un derecho de la desigualdad. Por su naturaleza el derecho consiste solo en la aplicación de una misma escala de medida. Pero los individuos desiguales (y no serían individuos diferentes si no fueran desiguales) solo son mensurables con la misma escala de medida cuando se los considera desde el mismo punto de vista, únicamente cuando se los comprende desde un determinado aspecto; por ejemplo, en el caso dado, solo considerarlos como trabajadores, no ver en ello otra cosa y prescindir de todo lo demás. Por otra parte, un trabajador está casado, el otro no, este tiene más hijos que aquel otro, etc. Suponiendo que el rendimiento del trabajo es igual y por ello igual la participación en el fondo social del consumo, uno recibe efectivamente más que el otro, este es más rico que aquel, etc. Para evitar todas estas dificultades, el derecho tendría que ser, no igual, sino desigual" (pp. 31-32). ciudadanía se basa en una abstracción de las relaciones de producción, es decir, se basa en la separación de lo político y lo económico (p. 107).

\section{NOTAS FINALES. LOS LÍMITES DE LA RENOVACIÓN CATEGORIAL}

En los trabajos de Agamben se encuentran proclamas o prédicas de una Comunidad que viene, de una política que viene, y la noción de refugiado se reivindica para solucionar una importante problemática que se plantea alrededor de los derechos humanos y la ciudadanía. Podría decirse que Agamben analiza la situación de los refugiados a partir de los estudios realizados por Arendt, quien había abordado un momento y espacio histórico preciso: la situación europea durante la primera posguerra y la Segunda Guerra Mundial. Así cuando Agamben se apropia de estas nociones teóricas, con ellas también se carga de un tiempo pasado en el cual no solo no existían prácticas que hoy sí existen, sino que tampoco se habían formulado declaraciones en materia de refugiados como el Estatuto del ACNUR, la Convención sobre el Estatuto de los Refugiados de 1951 y el Protocolo sobre el Estatuto de los Refugiados de 1967, entre otras. ${ }^{15}$

A pesar de lo anterior, podría sostenerse que la situación de los refugiados, la problemática de quienes viven actualmente en los campos de refugiados, continúa siendo agobiante y sus moradores se encuentran en una situación paradojal: «si bien se los expulsa por la fuerza de su país de origen, o se los atemoriza para que huyan, no se les permite la entrada a ningún otro» (Bauman, 2008a, p. 143).

En un contexto en el cual las personas desechables que genera el capitalismo ya no pueden ser absorbidas puertas afuera del capitalismo - puesto que este se ha instaurado a nivel global y entonces ya no hay afuera-, es decir, ante la imposibilidad de que la producción de individuos desechables por parte de los países centrales sea absorbida por los países periféricos, la solución parece ser la de producir refugiados (Bauman, 2008b: 28). Estos, para Bauman (2008b), se encuentran en un «espacio sin ley», en una situación en la cual carecen del

15 Así, en el continente africano se destaca la Convención sobre Refugiados (1969) y a nivel Interamericano la Declaración de Cartagena sobre los Refugiados (1984). 
respaldo de una autoridad legal que reivindique sus derechos, o hacia la cual hacerlos exigibles. Los refugiados "se encuentran hors du nomos ['fuera de la ley'], pero no fuera de esta ley o de aquella, ni la de este país o la de aquel otro, sino fuera de la ley como tal» (p. 32).

Además, y aunque aquí no lo haya abordado con profundidad, la distinción entre los ciudadanos $\mathrm{y}$ aquellos que no lo son se inscribe a la vez que reproduce discursos y políticas xenófobas. Muchas de estas políticas se traducen en cierre de fronteras, pero también y de modo complementario en prácticas de criminalización y persecución penal de aquellos que no son ciudadanos. Buena parte de los discursos y las prácticas punitivas se basan y reproducen construcciones de otredades, de enemigos, de chivos expiatorios y la existencia misma de la categoría de ciudadanía coadyuva a situar al extranjero como otro, como un enemigo. De esta manera, se configura una persecución punitiva hacia los no-ciudadanos, que en numerosos diseños institucionales cuentan con menor protección legal que los ciudadanos.

A la luz de lo desarrollado hasta aquí, la eliminación del concepto de ciudadanía, y todas sus implicancias jurídicas y políticas, no puede rechazarse. No obstante, si bien es posible acordar con la renovación categorial predicada por Agamben, también me parece necesario marcar ciertos límites de su propuesta. Desterrar la noción de ciudadanía puede tenerse como un avance que podría ubicarse en la esfera del Estado en términos de Marx, de lo público en palabras de Capella, y de lo político de acuerdo con la aproximación que propone Holloway. Incluso podría pensarse que representa un interesante y estimulante ajuste respecto de los desarrollos marxistas. Si en Marx, Capella y Holloway, la noción de ciudadanía constituía una igualdad meramente formal, aquello que podemos extraer de los postulados del autor italiano es que la noción de ciudadanía ni siquiera instituye una igualdad formal, puesto que, siempre ya, divide entre ciudadanos y no ciudadanos.

Creo que como bien nos insisten las tradiciones marxistas, la noción de ciudadanía predica una igualdad que no se corresponde con ciertas desigualdades y antagonismos que ubican en el plano privado, pero además, y ahora corrigiendo a los marxismos, ni siquiera logra colmar las expectativas de una igualdad formal predicada en el plano público: separando a los ciudadanos de quienes no lo son, crea desigualdades en el plano público y estatal. A los ojos de Marx (2004), los sujetos llevan una doble vida: a) una celestial, la de la comunidad política, en donde son iguales; y b) una terrenal, la de la sociedad civil, donde impera el egoísmo (p. 19). Sin embargo, el trabajo de Agamben nos permite hacer una corrección, puesto que ni aun en la vida celestial los hombres son iguales: algunos son ciudadanos del Estado y gozan de los derechos, pero quienes no son ciudadanos no tienen si quiera un reconocimiento formal de los derechos.

Avanzar en la igualdad a partir de la eliminación misma de la noción de ciudadanía constituye un notable progreso, pero no logra resolver los grandes desastres que se suscitan en el plano de la sociedad civil, en el ámbito privado de la economía. La eliminación de ciudadanía se inscribe en el cielo del Estado, pero como no tiene vinculación con la vida material de los individuos, su supresión no acaba con las desigualdades materiales.

Recordemos aquí el test que proponía Arendt para describir la crudeza de la situación de los apátridas durante la Segunda Guerra Mundial: analizar si el único modo de ingresar al sistema legal, y obtener de ello algún beneficio, era a través de la comisión de un delito. Lo cierto es que de acuerdo con lo que puede leerse en la edición del 21 de junio de 2011 del diario Washington Post —uno de los diarios más importantes de Estados Unidos, territorio donde Arendt escribió Los orígenes del totalitarismo-, James Verone, un ciudadano estadounidense desocupado, solo pudo ingresar al sistema de salud a partir de la comisión de un delito. Para lograr asistencia sanitaria gratuita, este ciudadano estadounidense de 59 años se presentó en un banco de Gastonia, perteneciente al Estado de Carolina del Norte, y entregó a una nota en la que decía: «Esto es un robo de banco. Por favor entrégueme solo un dólar» (Hugges, 2011). Luego buscó un asiento para aguardar la llegada de la policía para ser encarcelado y así obtener un tratamiento médico.

Lo que creo que está detrás del caso de Verone, que no es más que un caso paradigmático, son los límites del potencial que tiene la renovación categorial predicada por Agamben. Verone no era refugiado. Tampoco un apátrida. Era un ciudadano. Verone estaba dentro del sistema legal, no por ello estaba dentro del sistema de salud. No estaba fuera de la ley, pero la única 
vía que podía tomar para ingresar al sistema de salud era cometer un delito.

Teniendo en cuenta lo desarrollado, creo que es imperioso problematizar las desigualdades y catástrofes que trae consigo la noción de ciudadanía, y resulta necesario y hasta urgente desecharla. Sin embargo, tan importante como ello es dar cuenta de los límites que posee una renovación categorial que únicamente atienda ese aspecto. Si en lugar de pensarse a Verone a partir del concepto guía del ius del ciudadano se lo concibe a partir del refugium del individuo, y si se le aplica a Carolina del Norte la solución de aterritorialidad sugerida por Agamben, cuesta entender cómo se solucionarían las dolencias en su pecho y en su columna vertebral. Los urgentes cambios de categorías que propone Agamben, de ninguna manera logran resolver los dolores, también urgentes, de los miles de James Verone.

\section{REFERENCIAS}

Agamben, G. (1998). Homo sacer. El poder soberano y la nuda vida. Valencia: Pre-textos.

(2001). Medios sin fin: notas sobre la política. Valencia: Pre-textos.

(2008). Comentarios de Giorgio Agamben y debate final. En Z. Bauman, Archipiélago de excepciones (pp. 107-134). Buenos Aires: Katz.

Amiel, A. (2000). Hannah Arendt. Política y acontecimiento. Buenos Aires: Nueva Visión.

Arendt, H. (1994) We, refugees. En M. Robinson (Ed.), Altogether Elsewhere. Writers on Exile (pp. 110-119). Boston: Faber and Faber.

(1962). The Origins of Totalitarianism. Cleveland: Meridian Books.

Balibar, E. (2007). La impolítica de los derechos humanos. Arendt. El derecho a tener derechos y la desobediencia cívica. Revista Erytheis, 2, pp. 84-114.

Bauman, Z. (2008a). La sociedad sitiada. Buenos Aires: Fondo de Cultura Económica.

(2008b). Archipiélago de excepciones. Buenos Aires: Katz.

Benhabib, S. (2004). The rights of others. Aliens, Residents, and Citizens. Cambridge: Cambridge University Prees.
Brown, W. (1995). States of Injury. Power and freedom in late modernity. New Jersey: Princeton University Prees.

Capella, J. R. (1997). Fruta prohibida. Madrid: Trotta.

Castro, E. (2008). Giorgio Agamben. Una arqueología de la potencia. Buenos Aires: Unsam.

Heins, V. (2005). Giorgio Agamben and the Current State of Affairs in Humanitarian Law and Human Rights Policy. German Law Review, VI, 5, pp. 845-860.

Holloway, J. (1994). La ciudadanía y la separación de lo político y lo económico. En Marxismo, estado y capital (pp. 105-118). Buenos Aires: Tierra del Fuego.

Hugges, S. (21 de julio de 2001) James Verone robs bank to receive free health care. The Washington Post. Recuperado de http:// www.washingtonpost.com/blogs/blogpost/ post/james-verone-robs-bank-to-receive-freehealth-care/2011/06/21/AGxDrTeH_blog.html

Marx, K. (1973). Crítica del programa de Gotha. Buenos Aires: Anteo.

Sobre la cuestión judía. (2004). Buenos Aires: Prometeo.

Marx, K. y Engels, F. (2005). La ideología alemana. Buenos Aires: Santiago Rueda.

familia. Madrid: Akal.

(2013). La sagrada

Neal, A. (2007). Giorgio Agamben and the politics of the exception. Sexta Conferencia de relaciones internacionales paneuropeas, Turin. Recuperado de http://turin.sgir.eu/uploads/ Neal-Andrew $\% 20$ Neal $\% 20$ Georgio $\% 20$ Agamben $\% 20$ and $\% 20$ the $\% 20$ politics $\% 20$ of $\% 20$ the $\% 20$ exception.pdf

Rancière, J. (2004). Who is the subject of the rights of man? South Atlantic Quaterly, 103, 2-3, pp. 297-310.

Soto Carrasco, D. (2010). (im)Políticas del exilio. Intersticios. Revista sociológica de pensamiento crítico, IV, 2, pp. 251-257.

Žižek, S. (2005). Against Human Rights. New Left Review, 34, pp. 115-131 